\title{
Cortico-subthalamic inputs from the motor, limbic, and associative areas in normal and dopamine- depleted rats are not fully segregated
}

Citation for published version (APA):

Janssen, M. L. F., Temel, Y., Delaville, C., Zwartjes, D. G. M., Heida, T., De Deurwaerdere, P., VisserVandewalle, V., \& Benazzouz, A. (2017). Cortico-subthalamic inputs from the motor, limbic, and associative areas in normal and dopamine-depleted rats are not fully segregated. Brain Structure \& Function, 222(6), 2473-2485. https://doi.org/10.1007/s00429-016-1351-5

Document status and date:

Published: 01/08/2017

DOI:

10.1007/s00429-016-1351-5

Document Version:

Publisher's PDF, also known as Version of record

Document license:

Taverne

Please check the document version of this publication:

- A submitted manuscript is the version of the article upon submission and before peer-review. There can be important differences between the submitted version and the official published version of record.

People interested in the research are advised to contact the author for the final version of the publication, or visit the DOI to the publisher's website.

- The final author version and the galley proof are versions of the publication after peer review.

- The final published version features the final layout of the paper including the volume, issue and page numbers.

Link to publication

\footnotetext{
General rights rights.

- You may freely distribute the URL identifying the publication in the public portal. please follow below link for the End User Agreement:

www.umlib.nl/taverne-license

Take down policy

If you believe that this document breaches copyright please contact us at:

repository@maastrichtuniversity.nl

providing details and we will investigate your claim.
}

Copyright and moral rights for the publications made accessible in the public portal are retained by the authors and/or other copyright owners and it is a condition of accessing publications that users recognise and abide by the legal requirements associated with these

- Users may download and print one copy of any publication from the public portal for the purpose of private study or research.

- You may not further distribute the material or use it for any profit-making activity or commercial gain

If the publication is distributed under the terms of Article $25 f a$ of the Dutch Copyright Act, indicated by the "Taverne" license above, 


\title{
Cortico-subthalamic inputs from the motor, limbic, and associative areas in normal and dopamine-depleted rats are not fully segregated
}

\author{
Marcus L. F. Janssen ${ }^{1,2,3,4} \cdot$ Yasin Temel $^{3,5}$ - Claire Delaville $^{1,2}$ - Daphne G. M. Zwartjes ${ }^{6}$. \\ Tjitske Heida $^{6}$ Philippe De Deurwaerdère ${ }^{1,2}$ - Veerle Visser-Vandewalle ${ }^{7}$. \\ Abdelhamid Benazzouz ${ }^{1,2}$
}

Received: 15 July 2016/Accepted: 13 December 2016/Published online: 24 December 2016

(C) Springer-Verlag Berlin Heidelberg 2016

\begin{abstract}
The subthalamic nucleus (STN) receives monosynaptic glutamatergic afferents from different areas of the cortex, known as the "hyperdirect" pathway. The STN has been divided into three distinct subdivisions, motor, limbic, and associative parts in line with the concept of parallel information processing. The extent to which the parallel information processing coming from distinct cortical areas overlaps in the different territories of the STN is still a matter of debate and the proposed role of dopaminergic neurons in maintaining the coherence of responses to cortical inputs in each territory is not documented. Using extracellular electrophysiological approaches, we investigated to what degree the motor and nonmotor regions in the STN are segregated in control and
\end{abstract}

Abdelhamid Benazzouz

abdelhamid.benazzouz@u-bordeaux.fr

1 Univ. de Bordeaux, Institut des Maladies

Neurodégénératives, UMR 5293, 146, Rue Léo-Saignat,

33000 Bordeaux Cedex, France

2 CNRS, Institut des Maladies Neurodégénératives, UMR 5293, 33000 Bordeaux, France

3 School for Mental Health and Neuroscience, Maastricht University, Maastricht, The Netherlands

4 Department of Neurology, Maastricht University Medical Center, 6202 AZ Maastricht, The Netherlands

5 Department of Neurosurgery, Maastricht University Medical Center, 6202 AZ Maastricht, The Netherlands

6 MIRA Institute for Biomedical Technology and Technical Medicine, Department of Electrical Engineering,

Mathematics and Computer Science, Biomedical Signals and Systems group, Twente University, 7500 AE Enschede, The Netherlands

7 Present Address: Department of Stereotactic and Functional Neurosurgery, University of Cologne, Cologne, Germany dopamine (DA) depleted rats. We performed electrical stimulation of different cortical areas and recorded STN neuronal responses. We showed that motor and non-motor cortico-subthalamic pathways are not fully segregated, but partially integrated in the rat. This integration was mostly present through the indirect pathway. The spatial distribution and response latencies were the same in sham and 6-hydroxydopamine lesioned animals. The inhibitory phase was, however, less apparent in the lesioned animals. In conclusion, this study provides the first evidence that motor and non-motor cortico-subthalamic pathways in the rat are not fully segregated, but partially integrated. This integration was mostly present through the indirect pathway. We also show that the inhibitory phase induced by GABAergic inputs from the external segment of the globus pallidus is reduced in the DA-depleted animals.

Keywords Subthalamic nucleus - Cortico-subthalamic hyperdirect pathway - Motor cortex · Associative and limbic cortices · Parkinson's disease

\section{Introduction}

The subthalamic nucleus (STN) possesses a central position in the basal ganglia circuitry (Albin et al. 1989; Smith et al. 1998). Classically, the STN receives its input from the globus pallidus externus (GPe), as a part of the indirect pathway. In addition, a high density of cortical terminals is present in the STN; this monosynaptic cortico-STN projection is also known as the "hyperdirect" pathway (Nambu et al. 2002). As a driving force of the basal ganglia, the STN strongly controls the basal ganglia output nuclei by its excitatory glutamatergic efferents. Moreover, the STN is also an output nucleus itself by its efferent 
projections to the cortex (Miyachi et al. 2006; Degos et al. 2008). The key role of the STN in the basal ganglia motor and non-motor information processing is nicely reflected by its therapeutic role for Parkinson's disease (PD) in which it is the target of choice for deep brain stimulation (DBS). In MPTP-treated monkeys (Benazzouz et al. 1993, 1996) and later in PD patients (Limousin et al. 1995; Krack et al. 2003; Benazzouz et al. 1993, 1996; Janssen et al. 2014), STN DBS has been shown to potently alleviate the cardinal motor symptoms.

Currently, two major concepts of cortico-basal ganglia information flow exist: one supporting parallel information flow from functionally different cortical regions through the basal ganglia (Alexander et al. 1986; Alexander and Crutcher 1990; Groenewegen et al. 1990; Volkmann et al. 2010) and the other supporting integration of information coming from functionally different cortical regions (Percheron and Filion 1991; Percheron et al. 1984). In line with the concept of parallel information processing, the STN has been divided into three distinct subdivisions: a dorsolateral motor part, a medial limbic part, and a ventrolateral associative part (Parent and Hazrati 1995; Hamani et al. 2004; Temel et al. 2005).

Unfortunately, STN DBS does not only improve parkinsonian motor symptoms, but affects mood and cognition of PD patients (Temel et al. 2006; Visser-Vandewalle et al. 2005; Krack et al. 2003; Rodriguez-Oroz et al. 2004). The cognitive and psychiatric unwanted side-effects are supposed to be a result of the stimulation of the nonmotor parts of the STN (Temel et al. 2005) and could be prevented by selective stimulation of the motor area. Nevertheless, whether the motor and non-motor regions of the STN are segregated is still a matter of debate.

This study aimed to investigate to what extent information flow from the motor and non-motor cortical areas to the STN is segregated, or is being integrated through the direct monosynaptic cortico-subthalamic pathway and the indirect cortico-striato-pallido-subthalamic pathway. Using extracellular electrophysiological approaches in the rat, we performed electrical stimulation of different areas of the cortex and recorded STN neuronal responses. Then, we assessed the influence of DA depletion on the responses of STN neurons to cortical stimulation in the context of Parkinson's disease.

\section{Materials and methods}

\section{Subjects}

Male Sprague-Dawley rats (Centre d'Elevage Depré, Saint-Doulchard, France) weighing $250-400 \mathrm{~g}$ were kept at constant room temperature $\left(21.2^{\circ} \mathrm{C}\right)$ and relative humidity
(60\%), and had ad libitum access to water and food. All animal experiments were carried out in accordance with European Communities Council Directive 2010/63/UE. The study received approval from the local Ethics Committee (Bordeaux, France).

\section{6-hydroxydopamine lesions}

Details of the surgical procedure have been described earlier (Delaville et al. 2012). In brief, $1 \mathrm{~h}$ before surgery, rats were injected with desipramine $(25 \mathrm{mg} / \mathrm{kg}$, i.p., SigmaAldrich, Saint-Quentin Fallavier, France). Rats were anesthetized with ketamine $(75 \mathrm{mg} / \mathrm{kg}) / x y l a z i n e ~(10 \mathrm{mg} /$ $\mathrm{kg}$ ) and fixed in a stereotactic apparatus (Stoelting, Wood Dale, USA). The skull was exposed, and burr holes were made. Subsequently, 6-OHDA $(2.5 \mu \mathrm{g} / \mu \mathrm{l}$, in sterile $0.9 \%$ $\mathrm{NaCl}$ ) containing $0.1 \%$ ascorbic acid was unilaterally injected in the medial forebrain bundle at the following coordinates relative to Bregma (in $\mathrm{mm}$ ): $\mathrm{AP}-2.8$, $\mathrm{ML}-2$, DV -8.4 (Paxinos and Watson 1998). At the end of the injection, the cannula remained in place for an additional 2 min and was then withdrawn slowly from the brain to prevent reflux of the solution.

\section{Single-unit recordings of STN neurons}

Rats were anesthetized with urethane hydrochloride (1.2 g/ kg i.p., Sigma-Aldrich) and fixed in a stereotaxic apparatus (Horsley Clarke apparatus, Unimécanique, Epinay sur Seine, France). Body temperature was monitored with a rectal probe and maintained at $37{ }^{\circ} \mathrm{C}$ with a homeothermic warming blanket (model 50-7061, Harvard Apparatus, Les Ulis, France). Burr holes were made for stimulation and recording sites.

Extracellular recordings were performed with a glass micropipette, impedance 8-12 MOhms, containing 4\% pontamine sky blue dye dissolved in $0.9 \% \mathrm{NaCl}$. The pipette was lowered into the STN to record single-unit activity. The initial stereotactic coordinates relative to Bregma (in $\mathrm{mm}$ ) were: $\mathrm{AP}-3.8$ and $\mathrm{ML} \pm 2.5$. During penetration of the brain at the Bregma level of the STN, a characteristic burst firing of units was encountered in the thalamus. Then, the pipette passed through a silent zone before an area with spontaneous firing neurons was encountered. From the first trajectory, the recording electrode was moved in the medio-lateral and/or anteriorposterior plane to acquire neural responses in all STN subareas. Action potentials were amplified with a differential preamplifier (GRASS P15F, West Warwick, USA) and a differential amplifier (AM systems 1700, Sydney, Australia). The signal was displayed on a memory oscilloscope and registered on a computer (Scope 3.6; MacLab $4 \mathrm{~s}$ AD Instruments, Cambridge Electronic Design, UK). 
Spikes were separated from noise by a window discriminator apparatus (model 121, World Precision Instruments, UK) and sampled on-line (Spike 2 software, Cambridge Electronic Design, UK). At the end of each session, the last recording site was marked by electrophoretic injection of pontamine sky blue.

\section{Electrical stimulation of the prefrontal cortices}

A construction of two custom-made concentric electrodes was used for stimulation of five cortical regions ipsilateral to the recording site, namely the motor (MC), cingulate $(\mathrm{Cg})$, prelimbic (PrL), infralimbic (IL), and the agranular insular cortices (AI) (Tan et al. 2010). Stereotactic coordinates (in $\mathrm{mm}$ ) relative to Bregma were, respectively: AP 3.2, ML 4.0, VD -2.6 (MC); AP 3.2, ML 0.6, VD - 2.6 (Cg); AP 3.2, ML 0.6, VD -3.8 (PrL); AP 3.2, ML 0.6, VD -5.2 (IL); and AP 3.2, ML 4.0, VD -5.2 (AI) (Paxinos and Watson 1998) (Fig. 1a). Electrical stimuli were generated with an isolated stimulator (DS3, Digitimer Ltd., Hertfordshire, UK) triggered by a MacLab/4S system (AD Instruments, Castle Hill, Australia). Stimulation at each cortical region consisted of 200 monophasic pulses of $0.3 \mathrm{~ms}$ width and $300 \mu \mathrm{A}$ intensity delivered at a frequency of $1 \mathrm{~Hz}$. These stimulation parameters were chosen based on earlier studies (Fujimoto and Kita 1993; Maurice et al. 1999; Kolomiets et al. 2001). Using higher stimulation settings, STN neuronal responses increased. To prevent current spread to other cortical regions, the intensity was kept at $300 \mu \mathrm{A}$. The electrodes were moved up and down during the recordings to stimulate all targets. At each depth of the recording electrode, the delivery of stimulation pulses was preceded by a period of $10 \mathrm{~min}$ during which spontaneous activity was recorded. No qualitative differences in the response profiles were seen when moving the stimulation electrodes from the most dorsal cortical regions down to the most ventral cortical regions and back to the initial stimulation site.

\section{Histology and histochemistry}

At the end of experiments, animals were sacrificed, and brains were collected and frozen in isopentane at $-45^{\circ} \mathrm{C}$ and stored at $-80{ }^{\circ} \mathrm{C}$. Fresh-frozen brains were cryostatcut on glass into coronal sections $(30 \mu \mathrm{m})$ for localization of the stimulation track in the cortex and the pontamine sky blue dot in the STN. To this aim, acetylcholine esterase staining was used to contrast structures and to determine the location of the pontamine sky blue dot marking the last recording sites. Briefly, slides were air dried for $1 \mathrm{~h}$ and rinsed for $5 \mathrm{~min}$ in a sodium acetate buffer solution $(\mathrm{pH}$ 5.9). After pre-incubation for $15 \mathrm{~min}$ in a $0.375 \%$ glycine and $0.25 \%$ copper-sulfate sodium acetate buffer solution, slides were incubated in $200 \mathrm{ml} 0.375 \%$ glycine and $0.25 \%$ copper-sulfate sodium acetate buffer solution with $200 \mathrm{ml}$ acetylcholine iodide for $4 \mathrm{~h}$. Then, slides were washed for $5 \mathrm{~min}$ in the buffer solution, followed by a 2 min exposure to a $2 \%$ ammonium sulfide sodium acetate buffer solution. Finally, slides were rinsed 3 times in the buffer solution for 5 min. Histological evaluation of the brain sections confirmed that the electrodes traversed through the frontal cortex and reached a maximal depth of $5.2 \mathrm{~mm}$ according to bregma. Along the electrode trajectory, no additional histological damage was observed.

\section{Biochemistry}

For final analysis, the 6-OHDA-animals went through an additional validation step regarding the extent of DA depletion. This biochemical step was mandatory for the inclusion of the electrophysiology data from 6-OHDAanimals. Monoamine tissue levels were measured by highperformance liquid chromatography (HPLC) coupled with electrochemical detection (De Deurwaerdere et al. 1998) to evaluate the extent of the DA depletion. Tissue concentrations of the DA and metabolites 3,4-dihydroxyphenylacetic acid (DOPAC) and homovanillic acid (HVA) were measured in the anterior part of the striatum. At the end of electrophysiological recordings, rats were decapitated, and their brains were removed rapidly and frozen in cold isopentane. Both right and left portions of the anterior striatum were dissected and stored at $-80{ }^{\circ} \mathrm{C}$ until their use in biochemical assays. The tissues were homogenized in $200 \mu \mathrm{l}$ of $0.1 \mathrm{~N} \mathrm{HClO}_{4}$ and centrifuged at 13,000 rpm for $30 \mathrm{~min}$ at $4{ }^{\circ} \mathrm{C}$. Aliquots of the supernatants were diluted in the mobile phase and injected into the HPLC column (Chromasyl C8, $150 \times 4.6 \mathrm{~mm}, 5 \mu \mathrm{m}$ ) protected by a Brownlee-Newgard precolumn (RP-8, $15 \times 3.2 \mathrm{~mm}$, $7 \mu \mathrm{m})$. The mobile phase, delivered at $1.2 \mathrm{ml} / \mathrm{min}$ flow rate, was as follows (in $\mathrm{mM}$ ): $60 \mathrm{NaH}_{2} \mathrm{PO}_{4}, 0.1$ disodium EDTA, and 2-octane sulfonic acid plus 7\% methanol, adjusted to $\mathrm{pH} 3.9$ with orthophosphoric acid, and filtered through a $0.22-\mu \mathrm{m}$ Millipore filter. Detection of monoamines was performed with a coulometric detector (Coulochem I, ESA, Knivsta, Sweden) coupled to a dualelectrode analytic cell (model 5011). The potential of the electrodes was set at +350 and $-270 \mathrm{mV}$. Paired-sample $T$ tests were performed between the left and right side of the brain samples using the Statistical Package for the Social Sciences version 22.0 software (SPSS Inc, Chicago, Illinois, USA).

\section{Data analysis}

The basal firing rates and firing patterns of STN neurons were determined from the first $10 \mathrm{~min}$ of recording before 
A

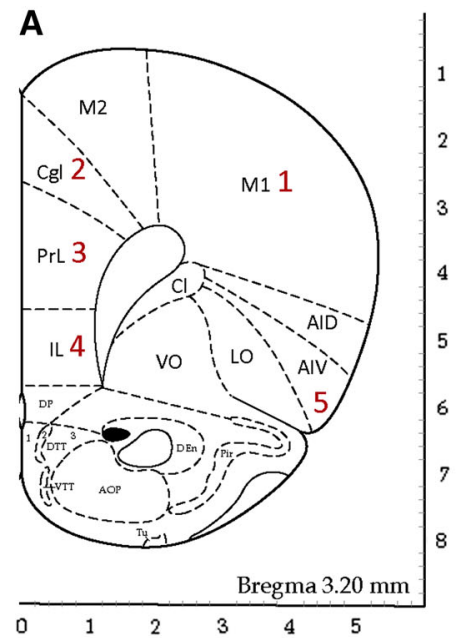

D

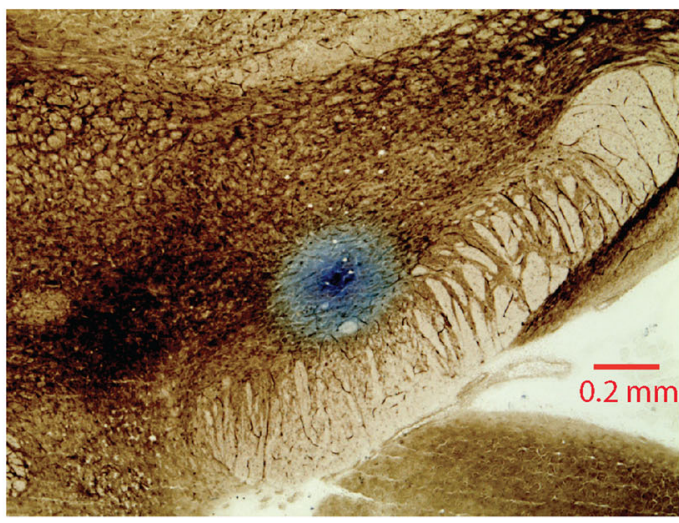

Fig. 1 a Illustration of the stimulation sites in the cortex. The two stimulation electrodes were moved up and down together along the same trajectories. Stimulation sites were: (1) the motor cortex (M1), (2) cingulate gyrus (Cg), (3) infralimbic gyrus (IL), (4) prelimbic cortex (PrL), and (5) agranular insular cortex (AI). b Representative example of baseline recordings from subthalamic nucleus neurons. c Representative example of a peristimulus time histogram showing a triphasic response of subthalamic neurons. First, an early excitation

stimulation of the cortical areas was started. The mean firing rate was calculated per neuron and a discharge density histogram was developed to assess the firing pattern using the Kaneoke and Vitek method (Kaneoke and Vitek 1996; Chetrit et al. 2009; Janssen et al. 2012). Firing patterns were classified as a 'random/irregular', 'regular', or 'burst' discharge pattern. The firing rate was compared between control and 6-OHDA-animals using a student $t$ test; firing patterns were analyzed using a Chi-square test. Peristimulus time histograms (PSTHs) were constructed from 200 consecutive stimulation trials with a bin size of $1 \mathrm{~ms}$ for each cortical stimulation site (MC, Cg, PrL, IL, and AI). The criterion used to establish the existence of an excitatory response corresponded to the mean of the number of spikes recorded during the $500 \mathrm{~ms}$ preceding the
C

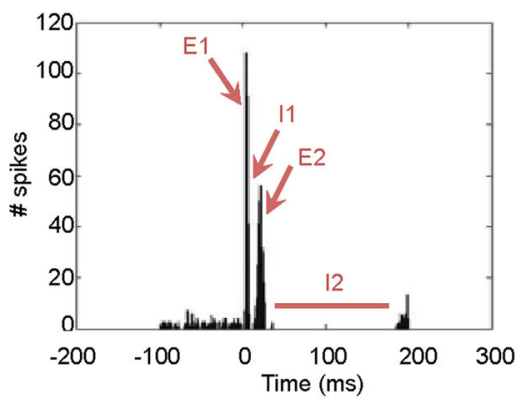

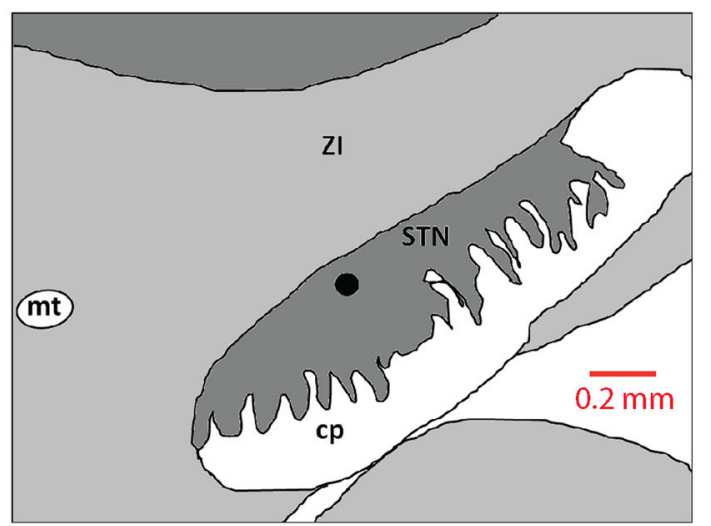

(E1) is seen followed by a late excitation (E2), between these excitatory phases, a short inhibition (I1) is present. After the triphasic response, a long-lasting inhibition (I2) is observed. d Representative example of iontophoretic blue dot in the subthalamic nucleus showing the last recording site of a trajectory, which was used to reconstruct the anatomical localization of the recorded neurons. STN subthalamic nucleus, $Z I$ zona incerta, $c p$ cerebral peduncle

onset of cortical stimulation plus the standard deviation (SD) of this mean. The latency of an excitatory phase was set at this time point. An inhibition was considered as a period during which the number of spikes is $50 \%$ below the mean of the number of spikes during the $500 \mathrm{~ms}$ period preceding the stimulation or if no spikes were recorded (Georges and Aston-Jones 2002; Beyeler et al. 2010; Kita and Kita 2011). To compare the neuronal responses between sham and DA-depleted animals, the average of responses was plotted as previously described (Kita and Kita 2011) and Student $t$ test was performed. Differences in neuronal responses in relation to the firing pattern were analyzed using a Chi-square test. Figures were made with Adobe Photoshop CS3 Version: 10.0.1 (Adobe, San Jose, USA) and MATLAB (The MathWorks, Natick, USA). 


\section{Results}

\section{Subthalamic neuronal responses to cortical stimulation in control animals}

In control animals, the electrical activity of 284 STN neurons was recorded. The spontaneous firing rate was $8.6 \pm 0.45$ spikes/s (mean \pm SEM) (Fig. 1b) and the firing pattern was regular in $60 \%$ of the recorded STN neurons, and irregular or bursty in $40 \%$ of the neurons. From the 284 STN recorded neurons, $79 \%(n=224)$ responded to the electrical stimulation of the MC, CG, PrL, IL, and/or AI cortices. Of all these responding STN neurons, 37\% $(n=83 / 224)$ showed a triphasic response [the early excitation (E1) and late excitation (E2) intervened by early inhibition (I1)], $10 \%(n=22 / 224)$ had only an early excitation (E1), while $37 \%(\mathrm{n}=83 / 224)$ had only a late excitation (E2), 3\% $(n=7 / 224)$ showed a combination of the early and late excitation and $13 \%(n=29 / 224)$ showed only the STN unspecific long-lasting inhibition (Fig. 1c).
These response patterns are in line with the previous reports (Kitai and Deniau 1981; Ryan and Clark 1991; Fujimoto and Kita 1993; Maurice et al. 1998; Kita and Kita 2011). No significant differences in the latency of the responses between different cortical stimulation sites were seen.

\section{Spatial distribution of STN neurons in relation with the corresponding cortical stimulation site}

Figure 1d, e shows an example of a pontamine sky blue dot marking the site of the last recorded neuron in the STN. The dots were used to reconstruct the location of the STN recorded neurons, as shown in Fig. 2. STN neurons responsive to motor cortex stimulation were present throughout the whole STN, but more sparsely within the ventro-medial part. Neurons responsive to stimulation of the associative-limbic cortices were more frequently found within the ventro-medial part of the STN. No differences were found in the localization of neurons showing a

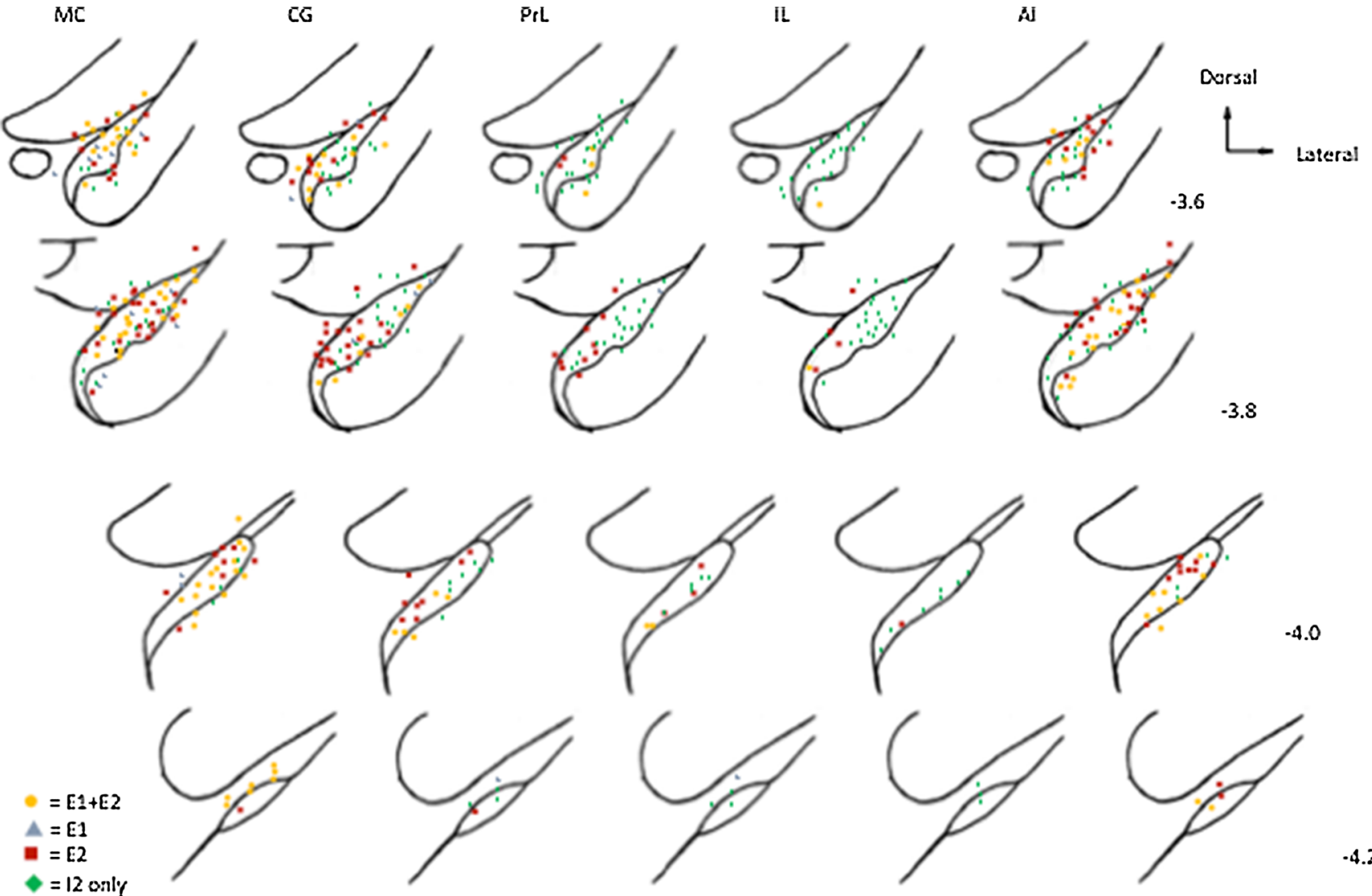

Fig. 2 Illustration of all the localizations of responsive and nonresponsive neurons per stimulation site, drawn after a reconstruction based on the identification of the last recorded neuron, which was marked by the iontophoretic injection of pontamine sky blue. Note that the responsive neurons to the motor cortex (MC) stimulation are mainly seen in the lateral parts of the STN. The neurons responsive to stimulation of the medial prefrontal cortical areas and the cingulate gyrus, for the most part, were located in the medial part of the STN. The neurons responsive to the agranular insular cortex seemed to be mainly located in the dorsal border of the STN. STN subthalamic nucleus, $A I$ agranular insular cortex, $C G$ cingulate gyrus, $D$ dorsal, $I L$ infralimbic cortex, $M$ medial, $M C$ motor cortex, $L$ lateral, $\operatorname{Pr} L$ prelimbic cortex, $V$ ventral 
triphasic response, or just a response to either the direct monosynaptic cortico-subthalamic pathway or the indirect cortico-striato-pallido-subthalamic pathway. Although a crude anatomical subdivision could be made between motor and non-motor areas within the STN, STN responses to motor cortex stimulation were not limited to the dorsolateral part of the STN. The same, though to a lesser extent, was observed for responses to limbic/associative cortices. Figure 3 illustrates representative examples of peristimulus time histograms of two neurons recorded one below another. The first neuron showed a triphasic response to MC, PrL, and AI stimulation, whilst the second one showed a late excitation to $\mathrm{CG}$ and PrL stimulation, and to a lesser extent also to the MC. In control animals, from the 284 neurons recorded in total, 513 neuronal responses from the STN were acquired by stimulation of the different cortical areas and most neurons responded to only one cortical region (Table 1). $41 \%$ of STN neurons, which were responsive to $\mathrm{MC}$ stimulation, did not respond to stimulation of the other stimulated cortical areas; nevertheless, $13.6 \%$ of the neurons showed an early response to both MC and AI, which originates from the monosynaptic corticosubthalamic pathway, even more neurons responded with a late excitation to stimulation of different cortical regions. Approximately, $60 \%$ of the short latency responses were seen selectively after stimulation of a single cortical area, but $40 \%$ showed overlap between regions. From the E2 responses, only $30 \%$ was selective (Table 2). This displays the integration of motor and non-motor cortico-subthalamic pathways. In five neurons, we tested if a combined stimulation of MC and CG would change the amplitude of the triphasic response when the neuron responded to separate stimulation of these cortical areas (Fig. 4). No increase in the amplitude of the early or late excitation was seen, although the onset and duration of the excitatory phases were shorter when stimulation was combined.

\section{Subthalamic neuronal responses to cortical stimulation in 6-OHDA-lesioned animals}

A total of 101 STN neurons were recorded in 6-OHDAlesioned animals. DA depletion was confirmed in the 6-OHDA-treated animals. In the lesioned side, the values of DA, DOPAC, and HVA were significantly lower compared to the non-lesioned side, with a reduction of 86,82 , and $81 \%$, respectively ( $p<0.01$, see Table 3 ). Compared to control animals $(8.6 \pm 0.45$ spikes/s), the spontaneous firing rate of STN neurons in DA-depleted animals significantly increased to $12.8 \pm 1.12 \mathrm{~Hz}$ (mean $\pm \mathrm{SEM,} t$ test, $p<0.01$ ). The firing pattern of STN neurons in 6-OHDAlesioned animals significantly changed compared to control animals (Chi-square test, $p<0.01) .44(44 \%)$ of the neurons discharged regularly and $57(56 \%)$ of the neurons showed an irregular or bursty pattern, in line with the previous studies (Hollerman and Grace 1992; Ni et al. 2001; Janssen et al. 2012). $88 \%$ of STN neurons $(n=89)$ responded to stimulation of different areas of the cortex $(\mathrm{MC}, \mathrm{CG}, \mathrm{PrL}, \mathrm{IL}$, and $\mathrm{AI}$ ), which was higher compared to control animals ( $t$ test, $p<0.001)$. Of all the responding STN neurons recorded in DA-depleted animals, 39 (39\%) showed a triphasic response and $3(3 \%)$ had only an early excitation (E1), while 25 $(25 \%)$ had only a late excitation (E2), 13 (13\%) a combination of the early and late excitation, and $9(9 \%)$ showed only the STN-specific long-lasting inhibition (Table 4). Interestingly, a trend towards an increased number of neurons which showed an excitation was seen compared to the control group. This trend was most clear in the type of responses in which a combined early and late excitation was present without the early inhibition in-between. However, these differences were not significantly different between control and DA-depleted animals (Chi-square test, $p>0.05)$. The same overlap of responses to the stimulation of different cortical areas was seen in 6-OHDA-lesioned animals compared to control animals (Table 2). The anatomical localization of neurons within the STN depending on the responsiveness to stimulation of a specific cortical area was the same for control and DA-depleted rats.

A comparison was made in the triphasic responses induced by motor cortex (MC) stimulation between control and 6-OHDA-lesioned animals. In Fig. 5, the average of triphasic response patterns is plotted for both groups. First, the latency between the stimulus and the beginning of the early excitation (E1) was the same in the control $(2 \mathrm{~ms})$ and $6-O H D A(2 \mathrm{~ms})$ groups ( $t$ test, $p>0.05)$. The duration of this phase was on average $2 \mathrm{~ms}$ longer in 6-OHDA-animals. The peak of the response was, respectively, 6 and $7 \mathrm{~ms}$ in the control and 6-OHDA-groups ( $t$ test, $p>0.05$ ). The total average (134 bins) of action potentials during the early excitatory phase (E1) is the same in both groups. Second, the latency between the stimulus and the beginning of the late excitation (E2) was equal in both groups (14 ms, $t$ test, $p>0.05)$. The duration of this phase was also the same and the peak of the response occurred at $20 \mathrm{~ms}$ in both groups. The total average (respectively, 285 and 277 bins in controls and 6-OHDA-lesioned animals) of action potentials during the late excitatory phase was not different in both groups ( $t$ test, $p>0.05$ ). It should be noticed that the inhibitory phase (I1) was less prominent in the 6-OHDA-lesioned animals compared to controls ( $t$ test, $p<0.05$; Fig. 5).

\section{Discussion}

Here, we showed that motor and non-motor cortico-subthalamic pathways in the rat are not fully segregated, but partially integrated. This integration was mostly present 
Fig. 3 Representative examples of the responses of two subthalamic nucleus neurons. The left column (ae) represents the responses of the first recorded neuron and the right column $(\mathbf{f}-\mathbf{j})$ represents the neuron recorded just below. The first neuron showed a triphasic response to motor cortex (MC, a), prelimbic cortex ( $\operatorname{PrL}, \mathbf{c})$, and agranular insular cortex (AI, e) stimulation. However, the second one showed a late excitation to cingulate gyrus $(\mathrm{CG}, \mathrm{g})$ and prelimbic cortex (PrL, h) stimulation, and to a lesser extent also to the motor cortex (MC, a). The vertical red line indicates the time point at which the stimuli were given
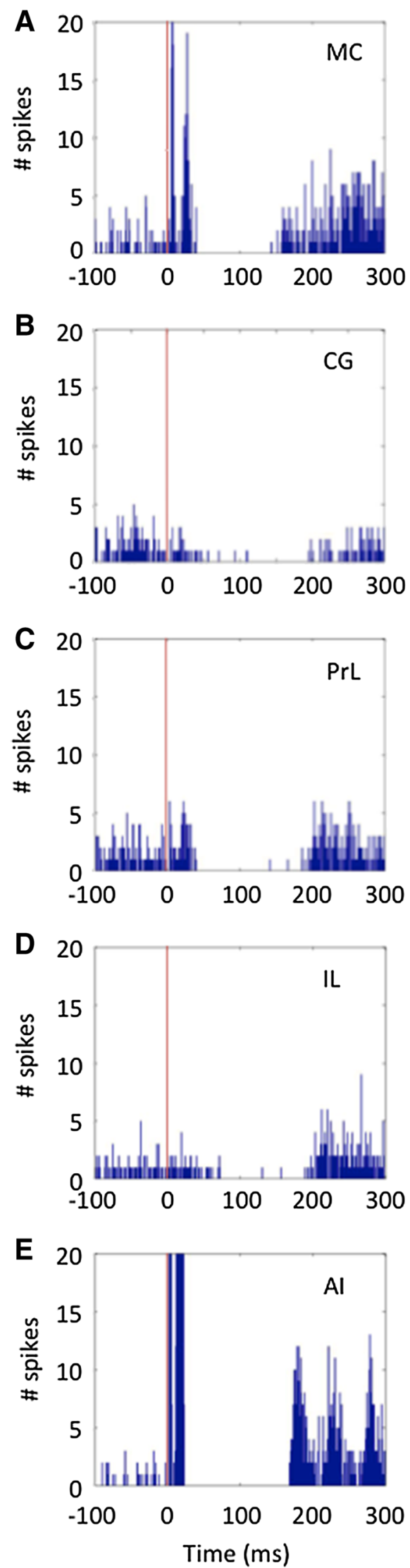
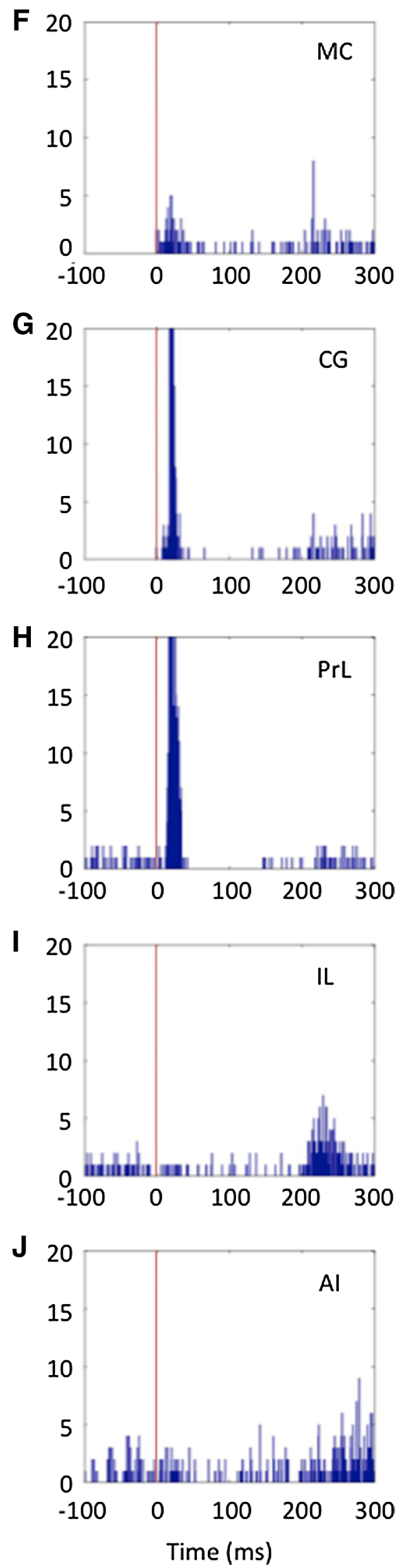
Table 1 Different responses of subthalamic nucleus neurons to the electrical stimulation of each cortical area in control rats

\begin{tabular}{lccrccc}
\hline $\begin{array}{l}\text { Cortical } \\
\text { areas }\end{array}$ & Triphasic & $\begin{array}{l}\text { E1/ } \\
\text { E2 }\end{array}$ & E1 & E2 & $\begin{array}{l}\text { Inhibition } \\
\text { only }\end{array}$ & Total \\
\hline MC & 55 & 5 & 20 & 36 & 24 & 140 \\
CG & 5 & 3 & 3 & 40 & 58 & 109 \\
PrL & 0 & 1 & 1 & 16 & 52 & 70 \\
IL & 0 & 0 & 0 & 9 & 58 & 67 \\
AI & 33 & 4 & 3 & 38 & 48 & 127 \\
Total & 87 & 13 & 15 & 96 & 240 & 513 \\
\hline
\end{tabular}

The total number of responses $(n=513)$ was recorded from 224 STN neurons

Note that most of the neuronal responses were induced by the motor cortex (MC) stimulation

Values are numbers of STN recorded neurons

$M C$ motor cortex, $C G$ cingular cortex, $\operatorname{Pr} L$ prelimbic cortical area, $I L$ infralimbic cortical area, AI agranular insular cortices, E1 early excitation, E2 late excitation

through the indirect pathway. The spatial distribution and response latencies were the same in the 6-OHDA-lesioned and sham animals. The inhibitory phase (I1) was, however, less apparent in the lesioned animals.

Our results showed that a large majority of STN neurons were responsive to cortical stimulation. From the responsive neurons, the majority responded to the stimulation of two or more cortical areas. Interestingly, responses to different cortical areas were mainly seen with a long latency. These long latency responses are related to the 'indirect' corticostriato-pallido-subthalamic pathway. The majority of neurons exhibit an inhibition phase alone in response to stimulation in the non-motor areas (CG, PrL, and IL). This is thought to be the result of a non-selective cortical depression after the stimulus. A substantial number of neurons also showed a short latency excitatory response mainly originating from the motor cortex, but was also seen after the stimulation of limbic/associative areas. This short latency response is caused by the excitation of STN neurons through the monosynaptic glutamatergic cortico-subthalamic pathway. Frequently, a combination of short and long latency responses was observed, which has earlier been characterized as a triphasic response (Fujimoto and Kita 1993; Kolomiets et al. 2001; Nambu et al. 2000; Magill et al. 2004).

A large number of STN neurons selectively responded to either motor or non-motor cortical regions with a crude topography. Indeed, the responsive neurons to motor cortex stimulation were mainly located in the lateral portion of the STN, whereas neurons responding to the stimulation of limbic/associative cortical areas were mainly seen in the
Table 2 Responses of subthalamic nucleus neurons to the electrical stimulation to one single ore to more than one cortical area in control and 6-OHDA-lesioned rats are illustrated

\begin{tabular}{|c|c|c|c|c|c|c|c|c|c|c|c|c|}
\hline \multirow{3}{*}{$\begin{array}{l}\text { Cortical areas } \\
\mathrm{MC}\end{array}$} & \multicolumn{4}{|l|}{ E1 } & \multicolumn{4}{|l|}{ E2 } & \multicolumn{4}{|l|}{ I2 } \\
\hline & \multicolumn{2}{|c|}{ Control } & \multicolumn{2}{|c|}{ 6-OHDA } & \multicolumn{2}{|c|}{ Control } & \multicolumn{2}{|c|}{ 6-OHDA } & \multicolumn{2}{|c|}{ Control } & \multicolumn{2}{|c|}{ 6-OHDA } \\
\hline & 28 & $39 \%$ & 15 & $21 \%$ & 24 & $14 \%$ & 18 & $13 \%$ & 23 & $4 \%$ & 15 & $4 \%$ \\
\hline $\mathrm{CG}$ & 7 & $10 \%$ & 10 & $14 \%$ & 18 & $11 \%$ & 12 & $9 \%$ & 16 & $3 \%$ & 8 & $2 \%$ \\
\hline Prl & 0 & $0 \%$ & 0 & $0 \%$ & 3 & $2 \%$ & 0 & $0 \%$ & 1 & $0 \%$ & 0 & $0 \%$ \\
\hline IL & 0 & $0 \%$ & 0 & $0 \%$ & 0 & $0 \%$ & 0 & $0 \%$ & 0 & $0 \%$ & 0 & $0 \%$ \\
\hline AI & 7 & $10 \%$ & 3 & $4 \%$ & 12 & $7 \%$ & 3 & $2 \%$ & 12 & $2 \%$ & 3 & $1 \%$ \\
\hline MC-CG & 0 & $0 \%$ & 1 & $1 \%$ & 8 & $5 \%$ & 9 & $7 \%$ & 55 & $10 \%$ & 31 & $9 \%$ \\
\hline MC-PrL & 0 & $0 \%$ & 0 & $0 \%$ & 6 & $4 \%$ & 8 & $6 \%$ & 44 & $8 \%$ & 28 & $8 \%$ \\
\hline MC-IL & 0 & $0 \%$ & 0 & $0 \%$ & 2 & $1 \%$ & 4 & $3 \%$ & 45 & $8 \%$ & 27 & $8 \%$ \\
\hline MC-AI & 28 & $39 \%$ & 36 & $51 \%$ & 53 & $31 \%$ & 52 & $39 \%$ & 75 & $14 \%$ & 72 & $21 \%$ \\
\hline CG-PrL & 1 & $1 \%$ & 4 & $6 \%$ & 13 & $8 \%$ & 13 & $10 \%$ & 55 & $10 \%$ & 36 & $10 \%$ \\
\hline CG-IL & 0 & $0 \%$ & 0 & $0 \%$ & 5 & $3 \%$ & 3 & $2 \%$ & 43 & $8 \%$ & 30 & $9 \%$ \\
\hline CG-AI & 0 & $0 \%$ & 1 & $1 \%$ & 4 & $2 \%$ & 5 & $4 \%$ & 49 & $9 \%$ & 27 & $8 \%$ \\
\hline PrL-IL & 0 & $0 \%$ & 0 & $0 \%$ & 6 & $4 \%$ & 2 & $1 \%$ & 40 & $7 \%$ & 23 & $7 \%$ \\
\hline PrL-AI & 1 & $1 \%$ & 0 & $0 \%$ & 6 & $4 \%$ & 3 & $2 \%$ & 42 & $8 \%$ & 22 & $6 \%$ \\
\hline IL-AI & 0 & $0 \%$ & 0 & $0 \%$ & 11 & $6 \%$ & 2 & $1 \%$ & 42 & $8 \%$ & 22 & $6 \%$ \\
\hline Total & 72 & $100 \%$ & 70 & $100 \%$ & 171 & $100 \%$ & 134 & $100 \%$ & 542 & $100 \%$ & 344 & $100 \%$ \\
\hline
\end{tabular}

Most neurons only responded to one cortical stimulation site, mainly to MC stimulation

Also note that most overlap was seen between MC and AI stimulation, a significant number of STN neurons responded to the electrical stimulation of both areas

Values are the number of responses of recorded neurons. Notice that one neuron can have both E1, E2, and/ or I2 responses

The total number in Italic corresponds to the total number of responses

$M C$ motor cortex, $C G$ cingular cortex, $\operatorname{Pr} L$ prelimbic cortical area, $I L$ infralimbic cortical area, $A I$ agranular insular cortices, $E 1$ early excitation, $E 2$ late excitation, $I 2$ late inhibition 
Fig. 4 Example of an STN neuronal response to stimulation of the MC (a), the CG (b), and the MC and CG combined (c). Abbreviations: cingulate gyrus (CG), motor cortex (MC). No increase in the amplitude of the early or late excitation was seen, although the onset and duration of the excitatory phases were shorter when stimulation was combined
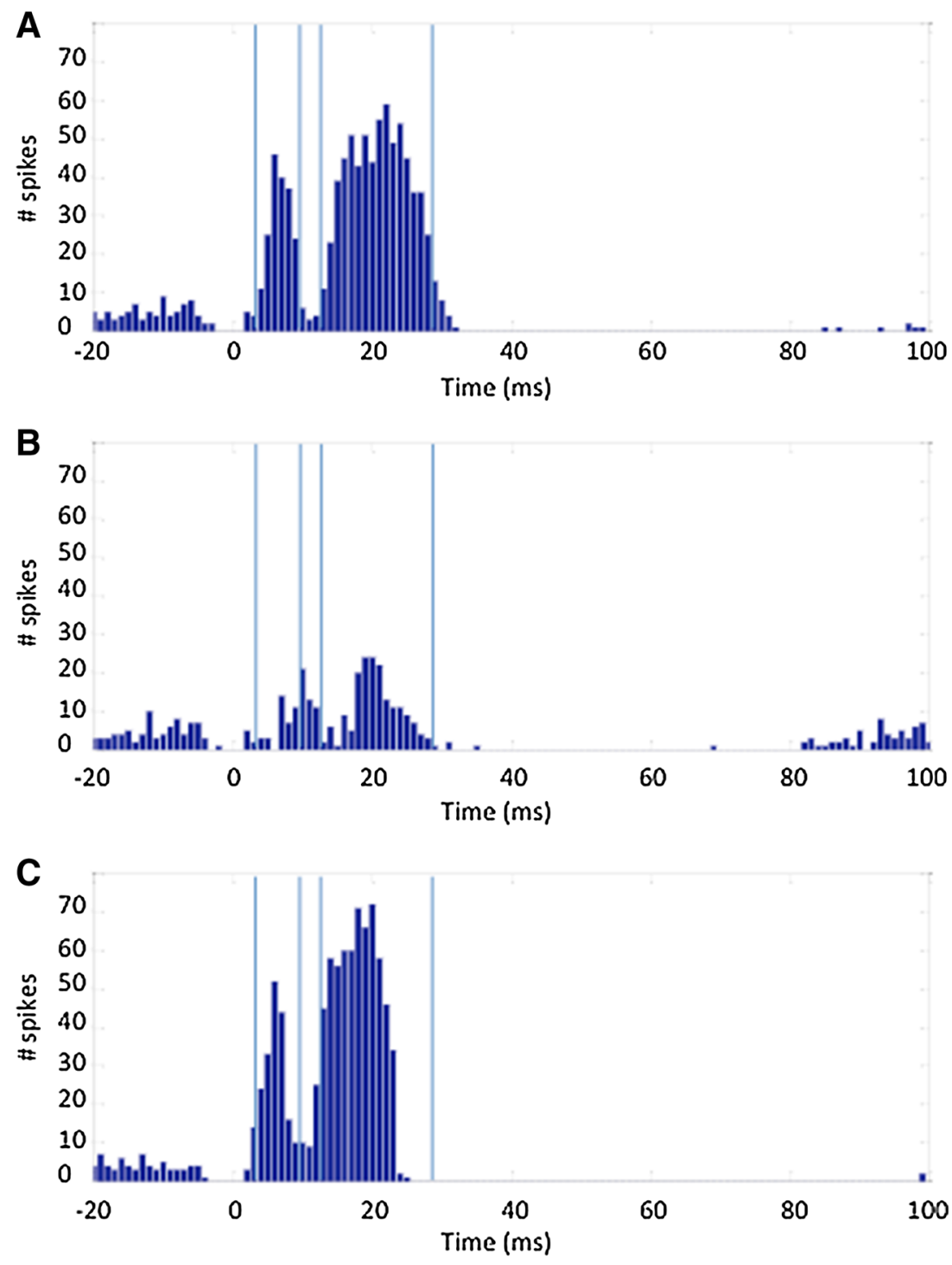

Table 3 Neurochemical analysis of unilateral 6-OHDA treatment induced depletion of dopamine and its metabolites. Tissue contents of striatal dopamine, 3,4-Dihydroxyphenylacetic acid (DOPAC), and homovanillic acid (HVA) measured by HPLC are depicted

\begin{tabular}{|c|c|c|c|c|}
\hline & \multicolumn{2}{|l|}{ Control } & \multicolumn{2}{|l|}{ 6-OHDA } \\
\hline & Left & Right & Left & Right \\
\hline Dopamine & $13,598 \pm 1367$ & $13,572 \pm 1149$ & $12,079 \pm 375$ & $1601 \pm 480^{* *}$ \\
\hline DOPAC & $01,726 \pm 135$ & $01,692 \pm 229$ & $01,780 \pm 109$ & $0319 \pm 76^{* *}$ \\
\hline HVA & $02,967 \pm 718$ & $02,603 \pm 651$ & $01,451 \pm 131$ & $0266 \pm 74 * *$ \\
\hline
\end{tabular}

Values are concentrations in $\mathrm{ng} / \mathrm{g}$ of wet tissue presented as the mean $\pm \mathrm{SEM}$

Paired-sample $t$ test was performed between the left side and right side of the brain samples

DOPAC 3,4-Dihydroxyphenylacetic acid, HVA homovanillic acid

$* * p<0.01$

medial parts of the STN. On the contrary, it should also be noticed that responsive neurons to the stimulation of motor and non-motor cortices were not limited to these areas and functional territories largely overlapped, as shown in
Fig. 3. Indeed, a significant number of STN neurons responded to stimulation of both motor and non-motor regions, with a long latency excitatory response and also with short latency responses. Therefore, our findings are not 
Table 4 Different responses of subthalamic nucleus neurons to the electrical stimulation of each cortical area in 6-OHDAlesioned rats

\begin{tabular}{lcccccc}
\hline Cortical areas & Triphasic & E1/E2 & E1 & E2 & Inhibition only & Total \\
\hline MC & 61 & 7 & 19 & 35 & 14 & 136 \\
CG & 8 & 4 & 4 & 37 & 34 & 87 \\
PrL & 2 & 1 & 1 & 15 & 33 & 52 \\
IL & 0 & 0 & 0 & 6 & 34 & 40 \\
AI & 41 & 4 & 4 & 36 & 27 & 112 \\
Total & 112 & 16 & 28 & 129 & 142 & 427 \\
\hline
\end{tabular}

Note that most of the neuronal responses were induced by the motor cortex stimulation

Values are the number of recorded neurons

$M C$ motor cortex, $C G$ cingular cortex, $\operatorname{Pr} L$ prelimbic cortical area, $I L$ Infralimbic cortical area, $A I$ agranular insular cortices, E1 early excitation, E2 late excitation
Fig. 5 Responses of subthalamic neurons in control and dopamine-depleted animals. The $x$-axis is time in milliseconds. Zero is the time of the electrical stimulus in the motor cortex. The $y$-axis represents the sum of action potentials per millisecond

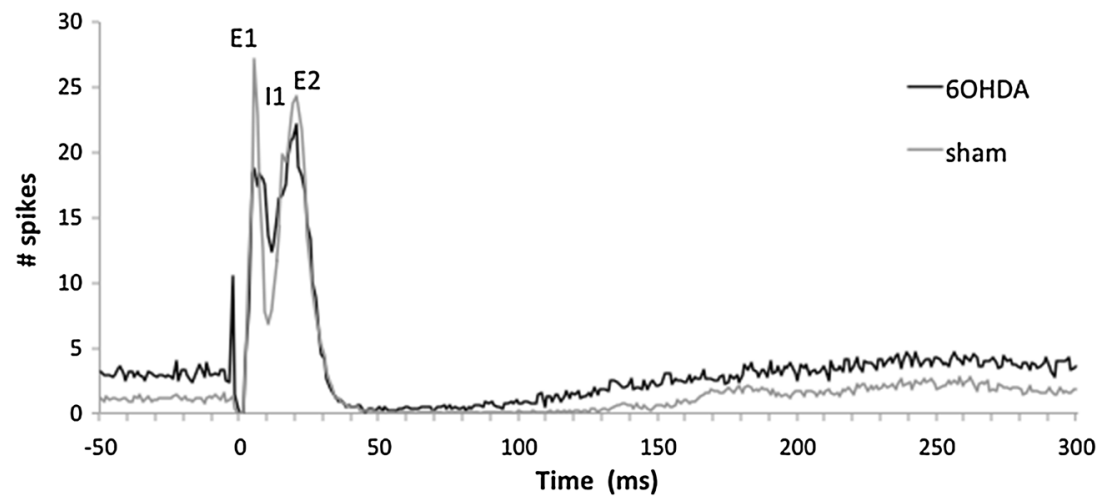

in line with the two major theories for cortico-basal ganglia information processing, which are based on studies in nonhuman primates and rodents. They do not support the absolute, parallel flow of motor, associative, and limbic informations through the cortico-basal ganglia circuits (Groenewegen et al. 1990; Volkmann et al. 2010; Alexander et al. 1986; Alexander and Crutcher 1990) and neither do these results support a pure convergence of these pathways (Percheron and Filion 1991; Percheron et al. 1984). Our findings in the rodent, however, are in agreement with another theory that presumes parallel cortico-basal ganglia pathways with an interaction between them (Joel and Weiner 1994). The concept that the cortico-basal ganglia circuits are not completely closed and segregated from each other has accompanied the principle of parallel organization in the first description of this network (Alexander et al. 1986). A review of anatomical studies showed that the cortico-basal ganglia network is interconnected by pathways, which are themselves components of the different loops within this network (Joel and Weiner 1994). Thus, with respect to our electrophysiological results, the organization of the cortico-subthalamic network is best described as functionally interconnected parallel loops. There are several arguments supporting this vision: first, dendrites extend across almost the entire STN (Hammond and Yelnik 1983); second, an anatomical tracer study has shown highly overlapping and fuzzy borders of somatotopic presentations in the STN (Kita et al. 2014), in agreement with our electrophysiological functional findings. The overlap between functional territories is also described in non-human primates. It is seen in projections from prefrontal, premotor, motor, and limbic projections to the STN (Nambu et al. 1996; Haynes and Haber 2013a), and the same overlap is seen in projections from the GPe (Kita 2007). In addition, an overlap is present in prefrontal-striatal projections (Haynes and Haber 2013b; Mailly et al. 2013). An even stronger argument is that responses to stimulation of the non-motor cortices have been seen in STN neurons, which also responded to motor cortex stimulation (Kolomiets et al. 2001). Moreover, when we stimulated two different cortical areas, the neuronal response was modulated. Other strong afferent projections to the STN from the ventral pallidum, intralaminar thalamic nuclei, and pedunculopontine tegmental nucleus also show overlapping functional anatomical projections (Groenewegen et al. 1993; Maurice et al. 1998). It is also not surprising that the corticosubthalamic pathways are not organized in a strictly parallel way, since interactions between associative, limbic, and motor circuits are necessary to perform complex tasks in stressful and highly demanding circumstances.

These findings are also clinically relevant. In Parkinson's disease, STN DBS is applied to improve motor 
symptoms. Therefore, the dorsolateral sensorimotor part of the STN is targeted. Many efforts are currently made to improve targeting to avoid undesired neuropsychiatric side-effects, which are thought to be caused by stimulation of the non-motor regions of the STN. If the interconnectivity of cortico-subthalamic pathways is as strong in humans as in rats, then selectively stimulating only the motor part is not possible with the current approaches. Indirect evidence is also given in a case report in which a hypomanic state was caused only by stimulation through one contact localized in the antero-medial STN, both this contact and the contact immediately dorsal to it improved the parkinsonian motor symptoms. The authors considered a model, based on detailed analysis of their data, in which the three functional modalities, emotional, cognitive, and motor, are not processed in a segregated manner but can be subtly combined in the small volume of the STN (Mallet et al. 2007). A molecular approach targeting specific cell populations might be a feasible option to be more selective (Schweizer et al. 2014).

In the 6-OHDA-lesioned rats, no differences were seen in the functional anatomical localization of STN neurons compared to the control group. Therefore, again, a crude spatial organization was seen, but with a great overlap. This finding illustrates that in a DA-depleted state, the somatotopy of STN neurons remains unchanged. Interestingly, as shown in Table 1, the interconnectivity of corticosubthalamic pathways was similar in the control and 6-OHDA-treated group.

The claim we make of integration of cortical information from motor and associative/limbic areas at the single neuron level of the STN requires selective stimulation of cortical areas. There are several arguments to be certain about this. First, the stimulation current intensity was applied using the concentric electrode design, which ensures that the electrical field does not extend outside the targeted areas and only neurons close to the electrode are being excited (Tan et al. 2010). Second, we have shown that some, but not all neurons showed responses to two different stimulated cortical regions. If coexisting responses were induced by current spread, then all the recorded neurons would have been responsive to both motor cortex stimulation as well as stimulation of the non-motor cortices.

Furthermore, we looked at the difference between the triphasic response in controls and 6-OHDA-lesioned animals. The main finding was the diminished inhibitory phase between the early and late excitation in the DAdepleted animals, which may explain the difference in the duration of the early excitation and the start of the late excitation between both groups. The reduced inhibitory phase might be the result of a reduced GABAergic input from the GPe to the STN of the indirect pathway. The diminished inhibition could be explained by the increased
GABAergic output from the striatum to the GPe in the DAdepleted state. This fit with an earlier study showing that responses from GPe neurons to cortical stimulation are decreased in the DA-depleted rat (Kita and Kita 2011).

In conclusion, our electrophysiological study showed that the neuronal responses to cortical stimulation of the STN are grossly anatomically organized with large overlap and interaction between different functional cortico-subthalamic pathways. For STN DBS in PD patients, this could suggest that avoidance of behavioral side-effects by selective stimulation of the motor part is hard to achieve with the current approaches, since a pure motor part may not exist. We also found that the inhibitory phase induced by GABAergic inputs from the GPe is reduced in the DAdepleted animals.

Acknowledgements The authors declare no competing financial interests. They gratefully acknowledge the support of the BrainGain Smart Mix Programme of the Netherlands Ministry of Economic Affairs and the Netherlands Ministry of Education, Culture and Science (Grant No.: SSM06011). The study was also supported by the "Bordeaux University" and the "Centre National de la Recherche Scientifique" (CNRS, France). M. Janssen received travel grants from the Boehringer Ingelheim Foundation and the Dutch Parkinson Association. C. Delaville was supported by a fellowship from the "Ministère de l'Education Nationale, de la Recherche et de la Technologie" (France). We thank L. Cardoit for her technical assistance. The authors declare no competing financial interests.

\section{References}

Albin RL, Young AB, Penney JB (1989) The functional anatomy of basal ganglia disorders. Trends Neurosci 12(10):366-375

Alexander GE, Crutcher MD (1990) Functional architecture of basal ganglia circuits: neural substrates of parallel processing. Trends Neurosci 13(7):266-271

Alexander GE, DeLong MR, Strick PL (1986) Parallel organization of functionally segregated circuits linking basal ganglia and cortex. Annu Rev Neurosci 9:357-381. doi:10.1146/annurev.ne.09. 030186.002041

Benazzouz A, Gross C, Feger J, Boraud T, Bioulac B (1993) Reversal of rigidity and improvement in motor performance by subthalamic high-frequency stimulation in MPTP-treated monkeys. Eur J Neurosci 5(4):382-389

Benazzouz A, Boraud T, Feger J, Burbaud P, Bioulac B, Gross C (1996) Alleviation of experimental hemiparkinsonism by highfrequency stimulation of the subthalamic nucleus in primates: a comparison with L-Dopa treatment. Mov Disord 11(6):627-632. doi: $10.1002 / \mathrm{mds} .870110606$

Beyeler A, Kadiri N, Navailles S, Boujema MB, Gonon F, Moine CL, Gross C, De Deurwaerdere P (2010) Stimulation of serotonin2C receptors elicits abnormal oral movements by acting on pathways other than the sensorimotor one in the rat basal ganglia. Neuroscience 169(1):158-170

Chetrit J, Ballion B, Laquitaine S, Belujon P, Morin S, Taupignon A, Bioulac B, Gross CE, Benazzouz A (2009) Involvement of Basal Ganglia network in motor disabilities induced by typical antipsychotics. PLoS One 4(7):e6208

De Deurwaerdere P, Stinus L, Spampinato U (1998) Opposite change of in vivo dopamine release in the rat nucleus accumbens and 
striatum that follows electrical stimulation of dorsal raphe nucleus: role of 5-HT3 receptors. J Neurosci 18(16):6528-6538

Degos B, Deniau JM, Le Cam J, Mailly P, Maurice N (2008) Evidence for a direct subthalamo-cortical loop circuit in the rat. Eur J Neurosci 27(10):2599-2610. doi:10.1111/j.1460-9568. 2008.06229.x

Delaville C, Chetrit J, Abdallah K, Morin S, Cardoit L, De Deurwaerdere P, Benazzouz A (2012) Emerging dysfunctions consequent to combined monoaminergic depletions in Parkinsonism. Neurobiol Dis 45(2):763-773. doi:10.1016/j.nbd.2011. 10.023

Fujimoto K, Kita H (1993) Response characteristics of subthalamic neurons to the stimulation of the sensorimotor cortex in the rat. Brain Res 609(1-2):185-192

Georges F, Aston-Jones G (2002) Activation of ventral tegmental area cells by the bed nucleus of the stria terminalis: a novel excitatory amino acid input to midbrain dopamine neurons. J Neurosci 22(12):5173-5187

Groenewegen HJ, Berendse HW, Wolters JG, Lohman AH (1990) The anatomical relationship of the prefrontal cortex with the striatopallidal system, the thalamus and the amygdala: evidence for a parallel organization. Prog Brain Res 85:95-116 (discussion 116-118)

Groenewegen HJ, Berendse HW, Haber SN (1993) Organization of the output of the ventral striatopallidal system in the rat: ventral pallidal efferents. Neuroscience 57(1):113-142

Hamani C, Saint-Cyr JA, Fraser J, Kaplitt M, Lozano AM (2004) The subthalamic nucleus in the context of movement disorders. Brain 127(Pt 1):4-20

Hammond C, Yelnik J (1983) Intracellular labelling of rat subthalamic neurones with horseradish peroxidase: computer analysis of dendrites and characterization of axon arborization. Neuroscience 8(4):781-790

Haynes WI, Haber SN (2013a) The organization of prefrontalsubthalamic inputs in primates provides an anatomical substrate for both functional specificity and integration: implications for Basal Ganglia models and deep brain stimulation. J Neurosci 33(11):4804-4814. doi:10.1523/JNEUROSCI.4674-12.2013

Haynes WI, Haber SN (2013b) The organization of prefrontalsubthalamic inputs in primates provides an anatomical substrate for both functional specificity and integration: implications for Basal Ganglia models and deep brain stimulation. J Neurosci 33(11):4804-4814. doi:10.1523/JNEUROSCI.4674-12.2013

Hollerman JR, Grace AA (1992) Subthalamic nucleus cell firing in the 6-OHDA-treated rat: basal activity and response to haloperidol. Brain Res 590(1-2):291-299

Janssen ML, Zwartjes DG, Tan SK, Vlamings R, Jahanshahi A, Heida T, Hoogland G, Steinbusch HW, Visser-Vandewalle V, Temel Y (2012) Mild dopaminergic lesions are accompanied by robust changes in subthalamic nucleus activity. Neurosci Lett 508(2):101-105. doi:10.1016/j.neulet.2011.12.027

Janssen MLF, Duits AA, Tourai AM, Ackermans L, Leentjens AFG, van Kranen-Mastenbroek V, Oosterloo M, Visser-Vandewalle V, Temel Y (2014) Subthalamic nucleus high frequency stimulation for advanced Parkinson's disease: motor and neuropsychological outcome after 10 years. Stereotact Funct Neurosurg 92(6):381-387. doi:10.1159/000366066

Joel D, Weiner I (1994) The organization of the basal gangliathalamocortical circuits: open interconnected rather than closed segregated. Neuroscience 63(2):363-379

Kaneoke Y, Vitek JL (1996) Burst and oscillation as disparate neuronal properties. J Neurosci Methods 68(2):211-223

Kita H (2007) Globus pallidus external segment. Prog Brain Res 160:111-133. doi:10.1016/S0079-6123(06)60007-1
Kita H, Kita T (2011) Cortical stimulation evokes abnormal responses in the dopamine-depleted rat basal ganglia. J Neurosci 31(28):10311-10322. doi:10.1523/JNEUROSCI.0915-11.2011

Kita T, Osten P, Kita H (2014) Rat subthalamic nucleus and zona incerta share extensively overlapped representations of cortical functional territories. J Comp Neurol 522(18):4043-4056. doi:10.1002/cne.23655

Kitai ST, Deniau JM (1981) Cortical inputs to the subthalamus: intracellular analysis. Brain Res 214(2):411-415

Kolomiets BP, Deniau JM, Mailly P, Menetrey A, Glowinski J, Thierry AM (2001) Segregation and convergence of information flow through the cortico-subthalamic pathways. J Neurosci 21(15):5764-5772

Krack P, Batir A, Van Blercom N, Chabardes S, Fraix V, Ardouin C, Koudsie A, Limousin PD, Benazzouz A, LeBas JF, Benabid AL, Pollak P (2003) Five-year follow-up of bilateral stimulation of the subthalamic nucleus in advanced Parkinson's disease. N Engl J Med 349(20):1925-1934

Limousin P, Pollak P, Benazzouz A, Hoffmann D, Broussolle E, Perret JE, Benabid AL (1995) Bilateral subthalamic nucleus stimulation for severe Parkinson's disease. Mov Disord 10(5):672-674

Magill PJ, Sharott A, Bevan MD, Brown P, Bolam JP (2004) Synchronous unit activity and local field potentials evoked in the subthalamic nucleus by cortical stimulation. J Neurophysiol 92(2):700-714. doi:10.1152/jn.00134.200400134.2004

Mailly P, Aliane V, Groenewegen HJ, Haber SN, Deniau JM (2013) The rat prefrontostriatal system analyzed in 3D: evidence for multiple interacting functional units. J Neurosci 33(13):5718-5727. doi:10.1523/JNEUROSCI.5248-12.2013

Mallet L, Schupbach M, N'Diaye K, Remy P, Bardinet E, Czernecki V, Welter ML, Pelissolo A, Ruberg M, Agid Y, Yelnik J (2007) Stimulation of subterritories of the subthalamic nucleus reveals its role in the integration of the emotional and motor aspects of behavior. Proc Natl Acad Sci USA 104(25):10661-10666. doi:10.1073/pnas.0610849104

Maurice N, Deniau JM, Glowinski J, Thierry AM (1998) Relationships between the prefrontal cortex and the basal ganglia in the rat: physiology of the corticosubthalamic circuits. J Neurosci 18(22):9539-9546

Maurice N, Deniau JM, Glowinski J, Thierry AM (1999) Relationships between the prefrontal cortex and the basal ganglia in the rat: physiology of the cortico-nigral circuits. J Neurosci 19(11):4674-4681

Miyachi S, Lu X, Imanishi M, Sawada K, Nambu A, Takada M (2006) Somatotopically arranged inputs from putamen and subthalamic nucleus to primary motor cortex. Neurosci Res 56(3):300-308. doi:10.1016/j.neures.2006.07.012

Nambu A, Takada M, Inase M, Tokuno H (1996) Dual somatotopical representations in the primate subthalamic nucleus: evidence for ordered but reversed body-map transformations from the primary motor cortex and the supplementary motor area. J Neurosci 16(8):2671-2683

Nambu A, Tokuno H, Hamada I, Kita H, Imanishi M, Akazawa T, Ikeuchi Y, Hasegawa N (2000) Excitatory cortical inputs to pallidal neurons via the subthalamic nucleus in the monkey. J Neurophysiol 84(1):289-300

Nambu A, Tokuno H, Takada M (2002) Functional significance of the cortico-subthalamo-pallidal 'hyperdirect' pathway. Neurosci Res 43(2):111-117

Ni ZG, Bouali-Benazzouz R, Gao DM, Benabid AL, Benazzouz A (2001) Time-course of changes in firing rates and firing patterns of subthalamic nucleus neuronal activity after 6-OHDA-induced dopamine depletion in rats. Brain Res 899(1-2):142-147 
Parent A, Hazrati LN (1995) Functional anatomy of the basal ganglia. II. The place of subthalamic nucleus and external pallidum in basal ganglia circuitry. Brain Res Brain Res Rev 20(1):128-154

Paxinos G, Watson C (1998) The rat brain in stereotaxic coordinates, 4th edn. Academic Press, New York

Percheron G, Filion M (1991) Parallel processing in the basal ganglia: up to a point. Trends Neurosci 14(2):55-59

Percheron G, Yelnik J, Francois C (1984) A Golgi analysis of the primate globus pallidus. III. Spatial organization of the striatopallidal complex. J Comp Neurol 227(2):214-227

Rodriguez-Oroz MC, Zamarbide I, Guridi J, Palmero MR, Obeso JA (2004) Efficacy of deep brain stimulation of the subthalamic nucleus in Parkinson's disease 4 years after surgery: double blind and open label evaluation. J Neurol Neurosurg Psychiatry 75(10):1382-1385

Ryan LJ, Clark KB (1991) The role of the subthalamic nucleus in the response of globus pallidus neurons to stimulation of the prelimbic and agranular frontal cortices in rats. Exp Brain Res Experimentelle Hirnforschung 86(3):641-651

Schweizer N, Pupe S, Arvidsson E, Nordenankar K, Smith-Anttila CJ, Mahmoudi S, Andren A, Dumas S, Rajagopalan A, Levesque D, Leao RN, Wallen-Mackenzie A (2014) Limiting glutamate transmission in a Vglut2-expressing subpopulation of the subthalamic nucleus is sufficient to cause hyperlocomotion.
Proc Natl Acad Sci USA 111(21):7837-7842. doi:10.1073/pnas. 1323499111

Smith Y, Bevan MD, Shink E, Bolam JP (1998) Microcircuitry of the direct and indirect pathways of the basal ganglia. Neuroscience 86(2):353-387

Tan S, Vlamings R, Lim L, Sesia T, Janssen ML, Steinbusch HW, Visser-Vandewalle V, Temel Y (2010) Experimental deep brain stimulation in animal models. Neurosurgery 67(4):1073-1079. doi:10.1227/NEU.0b013e3181ee3580 (discussion 1080)

Temel Y, Blokland A, Steinbusch HW, Visser-Vandewalle V (2005) The functional role of the subthalamic nucleus in cognitive and limbic circuits. Prog Neurobiol 76(6):393-413

Temel Y, Kessels A, Tan S, Topdag A, Boon P, Visser-Vandewalle V (2006) Behavioural changes after bilateral subthalamic stimulation in advanced Parkinson disease: a systematic review. Parkinsonism Relat Disord 12(5):265-272

Visser-Vandewalle V, van der Linden C, Temel Y, Celik H, Ackermans L, Spincemaille G, Caemaert J (2005) Long-term effects of bilateral subthalamic nucleus stimulation in advanced Parkinson disease: a four year follow-up study. Parkinsonism Relat Disord 11(3):157-165

Volkmann J, Daniels C, Witt K (2010) Neuropsychiatric effects of subthalamic neurostimulation in Parkinson disease. Nat Rev Neurol 6(9):487-498. doi:10.1038/nrneurol.2010.111 